\title{
Imagining Mundane Futures
}

\section{Sarah Pink and John Postill}

\begin{abstract}
Aвstract: When people move country, they experience new social, infrastructural, and ambient contingencies, which enables them to imagine otherwise unknowable possible futures 'at home'. In this article, we mobilise a design anthropological approach to show how collaboration with temporary migrants can generate understandings that generate insights regarding future sustainable products in emerging economies. We draw on research with temporary Indonesian student migrants in Australia, which explored how they envisioned their possible domestic futures through their changing laundry practices.
\end{abstract}

KeYwords: design anthropology, digital technologies, everyday life, futures, laundry, Indonesia, mundane practices, return migration

In this article, we propose a mode of anthropology that reflects on possible and imagined futures and how we might access these through a focus on mundane everyday activity. In doing so, we mobilise a design anthropological approach, drawing on recent interest in ethnographies of possible futures (Halse 2013) and in how technologies might figure in those futures (Pink et al. 2018). The context for our research was Indonesia's emerging economy, where an increasing number of women are working in professional roles and where the domestic technology market is growing. We draw on our research with middle-class Indonesian short-term migrants to Melbourne, Australia. Our project examined possibilities for environmentally sustainable domestic laundry amongst the emergent Indonesian middle classes, thus offering an ideal example through which to examine how mundane everyday practices are implicated in imagined futures. Participants who had moved between being busy professionals in Indonesia to students in Melbourne reflected on their past, present, and future lives and imagined possible everyday futures in their places of origin. Our research draws on and contributes to migration studies, the anthropology of ubiquitous everyday technologies, and research on middle-class Indonesian lives, and intervenes in these fields of study by inviting readers to consider them in relation to each other, rather than as separate areas of enquiry. Nevertheless the ultimate ambitions of this article are methodological, as we outline how our participants' reflections can be used to generate otherwise inaccessible insights into and visions of unknown futures.

Indonesia offered an ideal context through which to explore these possibilities precisely because it is considered to be a key emerging market, and its new and growing middle class has emerged as part of this context. In 2015, just after we concluded our fieldwork, the Australian Government Indonesia Country Brief reported that Indonesia was 'among the strongest-performing of the large emerging economies over recent years, ... the largest economy in Southeast Asia and fifteenth largest economy in the world'. This middle class comprised over 35 million Indonesians, according to Pam Nilan and colleagues, writing in 2011, and was projected to continue to grow (Nilan et al 2011: 710). Our research participants expected to return home on completing their studies in two to four years with new qualifications and professional possibilities. They consequently held hopes, visions, and aspirations for future ways of life that they were able to imagine because they had lived

Anthropology in Action, 26, no. 2 (Summer 2019): 31-41 (C) Berghahn Books and the Association for Anthropology in Action ISSN 0967-201X (Print) ISSN 1752-2285 (Online) doi:10.3167/aia.2019.260204

This article is distributed under the terms of the Creative Commons Attribution Noncommercial No Derivatives 4.0 International license (https://creativecommons.org/licenses/by-nc-nd/4.0/). For uses beyond those covered in the license contact Berghahn Books. 
abroad. Because all of the participants had moved to the same city, were graduates, and were students there (except one), they had common experiences. Thus we could focus on the specificity of each individual's trajectory while identifying patterns that emerged across the group.

Our research demonstrated how shifting infrastructures, material resources, social relationships, and ways of experiencing and imagining the world between Melbourne and Indonesia made it possible for participants to contemplate and play out new ways of living, everyday activity, and priorities. As Nikhil Anand and colleagues put it, 'material infrastructures ... are dense social, material, aesthetic, and political formations that are critical both to differentiated experiences of everyday life and to expectations of the future' (2018: 3). With participants, we compared their past domestic activities in Indonesia with their present lives as migrants to reveal how the infrastructures and contingencies of their everyday domestic lives were differently framed in both situations. Laundry offered a fruitful prism through which to examine this question, since it underpins much of everyday life in homes (Shove 2003; Pink et al. 2015) and in cities whereby 'this mundane object has had a mobile and shifting history enacting multiple socio-spatial, and gendered, relations and assemblages in the city, which have largely gone unnoticed in accounts of everyday urban life' (Watson 2015: 888). We explored how participants imagined their future lives in Indonesia both in relation to their recent and continued trajectories there and through the experience of living in Australia, which enabled them to imagine how digital technologies, washing machines, and sustainable laundry practices might configure in their possible future domestic lives in new ways. The findings of the study also invited us to consider the question of the emerging relationship between laundry and digital media. We return to these issues below in the discussion of our findings.

The study of the mundane has consistently been highlighted by scholars in cultural studies (Highmore 2011) and sociology (e.g. Shove 2003) as fundamental to understanding everyday life and the power relations in which it is implicated. Yet these single-discipline approaches are attached to theories that tend to be explicatory of what has already been evidenced as having happened, rather than exploratory of the possible or unknown. Design anthropology, in contrast, takes the ongoing emergence of everyday worlds (Smith and Otto 2016) and the creative and improvisatory nature of human activity within the contingent circumstances of the everyday
(Ingold 2013) as its theoretical starting points, and puts the concepts of uncertainty and possibility at its core (Akama et al. 2018). It thus offers an approach to understanding mundane everyday life (Pink et al. 2017) that disrupts the temporalities of conventional research in the social sciences through attention to possible futures (Pink and Salazar 2017). When it is brought together with the interests of non-academic research partners, it is a fundamentally applied anthropology (Pink 2017).

\section{Migration and Digital Technologies}

There is a significant critical anthropological literature relating to how migrants imagine their returns to their homelands. This literature emphasises that there are a range of feelings of dissonance related, for example, to the ways in which migrants themselves or their places of origin are perceived to have changed, particularly in the case of diasporic migrants (Tsuda 2019). In contrast, in our different group of student migrant participants such changes (in participants' practices and in local infrastructures) were anticipated as integral to starting a new life at home, with strong continuities to what was already known. These insights correspond with a growing social sciences and humanities literature about student migration. Existing research about international students and their experiences of migration in Australia in general and Melbourne in particular has focused on student well-being, social relationships, and social networks and identities with an emphasis on the difficulties that new students often experience (e.g. Fincher and Shaw 2011). There is also a growing literature about how transnational migrants use digital media to communicate with their families (Hjorth et al. 2018; Komito and Bates 2009; Madianou and Miller 2011; Titley 2008) and the cultural specificity of social media use (Miller 2011). Catherine Gomes and colleagues have found that because social media plays a role in students' maintaining 'contact with friends and family from the home nation [it] may assist students with forming imaginary bonds with their homelands' and provide them with support networks that help them to form social relationships with students from elsewhere while away (2014: 13). There is additionally an emerging literature about domestic life and migration. Of specific relevance to this article is Cecily Maller and Yolande Strengers' research into the domestic practices of student migrants in Melbourne. Maller and Strengers show that "migrants "carry" practices which can "travel" 
between and across cultures, generations and living arrangements', and that 'on encountering new practices in the destination country, ... the practices carried by migrants are subject to various forms of integration, disintegration and transferral across generations' (2013: 243). Together, these existing studies imply that student migrants may keep their relationships at home active when away and develop practices of resource and technology use that also connect with those used at home.

Our research with participants was situated in relation to both their own discussions of the cultural, social, technological and infrastructural contexts of their everyday domestic and digital lives in Indonesia and to the wider academic literature about domestic and working lives, the water and energy infrastructures that served as resources for laundry, and domestic technologies and digital media use in Indonesia. Existing research suggests that there is a two-tiered Indonesian middle class - part established, part emergent and aspirational, and related to residential status, professional competencies, and being digitally connected (see Simone and Fauzan 2013) - that is characterised by forms of consumption that might be conspicuous (e.g. Ansori 2009) but that could also be restrained and morally/religiously informed (e.g. Jones 2010). For Indonesian women, developing a professional career is possible, but complicated by their commitment to the domestic sphere. Women tend to either leave work and seek to continue their careers while working from home once they have children, or develop collective solutions involving family members, child-minders, and maids (e.g. Kismono 2011; Melissa et al. 2013; Nilan and Utari 2008). Indonesian women living in family households can be seen as domestic managers (even if not domestic workers) taking responsibility for the running of their homes, including ensuring that the laundry is done.

Another important aspect of the lives of the Indonesian middle classes is their digital media use. In 2016 the management consultancy McKinsey \& Company reported that Indonesians 'spend a higher than-average amount of time on the Internet, primarily engaging in heavy social media usage and e-commerce', and that 'Their social media usage is among the highest of any population in the world; Jakarta is widely considered the Twitter capital of the world' (Das et al 2016: 9)

In Indonesia, the Internet is predominantly accessed via smartphones, which is related to its limited broadband and Wi-Fi infrastructures, as the low level of bandwidth and computer penetration in Indonesia have contributed significantly to the challenge of increasing Internet penetration in the country' (Carrieri et al. 2013). Jakarta's water infrastructures have been described as part of the city's 'cluttered' urban landscape, where 'spaces both beneath and above the city are traversed by a "tangled network" of public, private and communal infrastructure for accessing, filtering, and distributing a variety of water sources' (Kooy and Bakker 2008: 376). It was also found that in the cities of Bandung and Yogyakarta, respectively, 58 per cent and 81 per cent of households sampled had water pumps, again signalling the problems relating to water infrastructure in these cities (Wijaya and Tezuka 2013).

While the existing literature about student migration and about information and communication technologies (ICT) and migration tends to be concerned with migrant social relations, well-being, identity, and/or technology use (and to some extent administration systems), migration does not only involve moving from one physical locality and set of social, bureaucratic, and technological relations to another. It also entails other shifts, one of which is a shift in infrastructure, which 'is an integral and intimate part of daily social life' (Anand et al. 2018: 6). When we put washing machines and digital media use at the centre of a study of migration to compare how these were used in Indonesia with how they are experienced in Australia, these reconfigurations came into view. For instance, while global digital infrastructures enable continuous online contact, once overseas this online contact is experienced differently since it will be combined differently with face-toface relationships and framed by national digital infrastructures and modes of accessing the Internet. Similarly, different domestic technology designs (e.g. front-loader instead of top-loader washing machines) and types of products may predominate in different local markets. Likewise, domestic resources like water and electricity may be differently accessed and have different infrastructures, payment systems, and perceived quality.

The studies cited above provide a key background to our work, yet they tend to treat domestic routines such as laundry and the use of digital media as separate activities. Our interest follows existing design anthropological research, which has shown how people improvise in contingent circumstances to use different technologies as part of the same activity. It has been argued that this can occur in such a way that hybrid technologies (such as the bringing together of the car and smartphone) are formed (Pink et al. 2018). Here, we are concerned with the example 
of how digital media and laundry are, in small and almost invisible, or unnoticed, ways, beginning to become part of the same processes, and with the implications of this for possible futures.

\section{Participants and Methods}

All the participants had recently moved from Indonesia to Melbourne when we undertook our research between February and April 2014. Being educated overseas is not an unusual aspiration for middleclass Indonesians or for their children, and there is significant middle-class Indonesian student migration to Australian cities; 'Indonesia was the seventh largest source of international students in Australia in 2013 with 13,300 students enrolled in over 17,100 courses' (DFAT N. D.). Moreover, Ruth Fincher and Kate Shaw (2011: 539) cite existing studies to note that 'Melbourne is one of several cities in Australia in which the proportion of the world's "cross-border" students has increased dramatically over the last two decades'. To undertake our own research, eight participants were recruited through networks and snowballing, and, given the detail that was produced through our video ethnographic encounters with participants, as outlined below, were a sufficient sample size to produce relevant insights. All participants were interested in and keen to participate in our research. ${ }^{1}$ They were aged between 27 and 45 and included one couple.

All the participants had university degrees to at least undergraduate level and had worked in Indonesia between finishing university and coming to Australia. Some had set up family homes in Indonesia, but none were experienced in using the washing machines they encountered when they arrived. For men participants, this was largely due to gendered divisions of labour at home. One woman had her own washing machine in Indonesia, but this was a twin-tub machine and thus different from the toploader she used in Melbourne. They were part of a generation of middle-class people for whom having a washing machine was part of the notion of living in an adult home. When they were growing up, their parents (usually the mother) either hand-washed their clothes or had the washing done by a maid. Most of their parents now had washing machines. However, during their own young adult independent lives most of our participants did not do their own laundry, either by hand or by using a machine, but outsourced it to a laundry service (with the exception of their underwear, which they might hand- wash themselves). They were now learning to use washing machines for the first time.

Most participants anticipated returning to Indonesia to live within the next two years, one within four years, and they maintained close contact with their personal networks in Indonesia. Those who had been in Melbourne longer had relatives in Indonesia and returned often enough to have both a good knowledge of how other people were currently doing laundry in Indonesia and a vision (based on their own investigations) about what their everyday lives would be like when they returned.

Our research methods were an adaptation of indepth interviewing, video tour, and re-enactment methods developed by Pink for researching everyday life in the home, at the laundry, and with digital technologies (e.g. Pink and Leder Mackley 2014). Interviews were undertaken with all participants, and video methods were used with all but two who used shared facilities. The interviews focused on participants' migration, domestic and professional, laundry, and digital media biographies in Indonesia, on how these had shifted when they had moved to Melbourne, on the ways that they practically engaged with and experienced local water, energy, and broadband infrastructures, and on how they imagined their digital and laundry futures back in Indonesia. Participants led video tours of their homes, which enabled them to select what they showed and to explore how and where laundry and digital media were used in everyday life in the home. Finally, participants demonstrated how they did their laundry, from where it was kept to when it was hung out to dry. These video-recorded enactments were performative and conversational, and examined what participants usually did and how it felt emotionally and sensorially to do it. Such methods are suitable for researching activities dispersed across daily and weekly routines. We combined Pink's expertise in laundry and digital media in domestic life with Postill's expertise in digital media in South East Asia and in Indonesian language and culture. We interviewed two participants in Indonesian and the others in English. When concepts were difficult to explain in English we discussed the Indonesian meanings with participants.

Further fieldwork was undertaken with eight households in Yogyakarta in Indonesia, and Postill and the filmmaker Nadia Astari undertook an in depth audio-recorded interview with the person responsible for laundry, a video interview, and a video tour of the home. All but two were Muslim families. All the women participants worked, and five participants had the help of a maid or house assistant. In 
contrast to the participants in the Melbourne study, they were aged between 30 and 50 years old, all had children, and all were living in established homes with their own washing machines. This stage has been published in the form of a documentary film, Laundry Lives (Pink and Astari 2015). We do not discuss the findings of this stage in detail here, but reference them for comparison.

\section{Migrant Laundry: Ethnographic Examples}

In this section, we examine three key themes to build a picture of how participants engaged with laundry in relation to digital technologies once in Melbourne, and how they imagined these technologies in their aspirational futures.

\section{Washing Machines and Environmentally Sustainable Products}

While there is growing awareness about environmental issues amongst the middle classes in Indonesia, we found little evidence of awareness about or commitment to environmental sustainability through everyday life activities, such as saving water and energy or using environmentally friendly products, amongst the wider population. Our research in Indonesia showed that some middle-class participants were interested in environmental issues and willing or keen to do their laundry in ways that were environmentally sustainable. However, the contingencies of everyday life, technologies, and infrastructures and the lack of availability of environmentally sustainable products created restrictions. Some took small measures, such as using less detergent or water, or using the washing machine at times when they believed it would consume less energy. However, no participants used environmentally sustainable products, citing lack of availability and arguing that those they had tried did not clean their clothing sufficiently well (Pink and Astari 2015). The Melbourne-based participants described the difficulties of living environmentally sustainable lives in Indonesia similarly.

For instance, Retno was aware of and cared about environmental issues. She complained when Indonesians bought foreign bottled water rather than boil their water, emphasising that 'part of my conscience is what we drink' and that the brand that she purchased was important. Retno was also conscious of water use and usually took a quick five-minute shower, since 'it's just to clean our bodies, why should we spend thirty minutes in the bathroom?' Yet she admitted that the reason she had become more conscious about electricity use in Melbourne was because it was more expensive, whereas in Indonesia her concession was that 'I always turn the light off when I leave home; that's the way I show my conscience'. However, her priorities required using water and energy. While her good lighting habits showed her sentiments about energy, it was important for Retno to have up-to-date digital technologies ('gadgets') at home. Similarly, Rizaldi was concerned about using up the ground water, yet his family of four would bathe three times a day. Wulan explained the issues in the following way: 'If you really care about climate change, you will ride a bike, but it's really hard in Jakarta to feel comfortable in the street'. She drove because 'public transportation is not really comfortable and riding [a] bicycle is not really comfortable, so I'm still using my car'. She explained that 'it's not really showing that I care about climate change. But for the other things like littering and using water wisely, I try to do ... in respect of climate change'.

A comparison of participants' accounts of their lives in relation to environmental sustainability in Indonesia with those in Melbourne shows how living in new circumstances creates new priorities. In Melbourne, participants' attachments to previously 'normal' everyday conventions had been disrupted, including their having to do their laundry themselves. The social collective is emphasised as providing support and solutions for everyday life in Indonesia, for both domestic and other issues (Kismono 2011: 23; Nilan et al. 2011: 724). Our participants in Indonesia consistently resolved the problems related to their busy professional and domestic lives through the collective rather than individually. Domestic tasks including cleaning, laundry, and childcare were achieved in various combinations between husbands and wives, members of extended families, and maids or house assistants or external services (Pink and Astari 2015). In Melbourne, although students actively developed networks to advise and support each other, the human resources of the collective were not there hands-on to help, and paid help was considered unaffordable. While participants maintained close contact with family and friends in Indonesia via social media, they could no longer draw on their physical help. Therefore, they had to learn to do laundry, and in doing so they adopted various environmentally sustainable approaches.

The most obvious was the use of environmentally friendly laundry detergents and conditioners, both of which were readily available in Melbourne. A particular brand, cheaper than others, was popular be- 
cause saving money was also a priority. Participants saw this as an opportunity to use environmentally friendly products, but doubted they would be able to continue doing so on returning to Indonesia due to lack of availability and quality. Another move towards sustainability was using a short washing-machine cycle, thereby consuming less water and energy. Two participants used this approach, telling us that their clothes did not need washing for longer to be clean and saw this as a way of caring for them by preventing damage through over-washing.

Other circumstances also enabled environmentally friendly approaches to laundry. For Indonesian and Melbourne-based participants, being well dressed was essential in Indonesian professional life. In Indonesia, clothing is frequently washed due to the hot weather, is changed three times daily, and must be clean and ironed when worn for work or going out. In Melbourne, participants did not feel that they needed to either change their clothes so often or dress as formally. For instance, Retno, wearing bright shorts with tights and a T-shirt, said that she could not go to work dressed like that in Indonesia. Likewise, ironing was not considered as important in Melbourne. For one participant, you 'don't need to iron things here [in Melbourne]' but in Bali 'you pretty much iron everything'. She related this to both the humidity in Bali and to the fact that 'in Indonesia you would probably see all the wrinkles'. She had done little ironing in Indonesia, having had a maid at her parents' house and having used a laundry service upon leaving home: she only ironed things one-byone if needed. Another participant suggested that in contrast to Melbourne, where she felt that it did not matter so much what people wore, in Indonesia people would judge her by her clothes, which needed to be ironed, and that the texture of clothing was created by ironing. The couple participating together also emphasised the importance of wearing unwrinkled, ironed clothes in Indonesia. Thus, in Melbourne the need to wash and iron became less frequent.

Participants in Melbourne and Indonesia were concerned that their clothing could be damaged though machine-washing. They tended to wash delicate items by hand in order to preserve their life and quality. One Melbourne participant was so concerned that there would not be an appropriate hand-wash product for her clothes in Melbourne, that she brought one from Indonesia, but she had not used it because on arriving she began to put her underwear in the washing machine in a zip-up net. In Melbourne, participants generally cared for their clothes less. Whereas in Indonesia most washed their underwear separately by hand, once in Melbourne and once they used washing machines none did so. A comparison of the careful ways that participants and maids / house assistants loaded washing machines in Yogyakarta with the more haphazard methods used by Melbourne participants suggests that while away they felt they did not need to perform these timeconsuming ways of caring for laundry.

Once in Australia, participants learnt to use washing machines in a context where they could depart from conventions driven by commitments to, and concerns about, protection from damage, self-presentation, and cleanliness, because the social, cultural, and technological environments that they inhabited had shifted. These experiences of learning to launder were part of the process through which participants could imagine their future uses of washing machines and environmentally friendly products in Indonesia.

\section{The Relationship between Digital Media and Laundry}

Social media were important to Melbourne participants at home and in Melbourne. We will first outline the context of their use of digital technologies before examining how their use of social media was entangled with laundry. Almost all the participants were, to varying degrees, routine checkers of social media and email on their iPhones and were frequent users of Facebook, Twitter, WhatsApp, and Path. They used or had used their smartphones and social media socially, professionally, and for running small businesses or selling online. New relationships between digital media and laundry grew once the participants were in Melbourne.

Even amongst more reluctant users who did not ascribe to conspicuous consumption and the need to have the 'latest' gadget, a more inconspicuous consumption of functionally up-to-date technologies was found to be important. Retno introduced herself as 'a gadget freak'. She explained that she always had up-to-date technologies and a lot of technologies, some of which initially seemed like duplicates. However, there was a practical explanation for this, because in Indonesia she sometimes worked in the outer islands, where there are often electricity problems. So she had two laptops, a Samsung tablet, an HDC phone (for when there was no smartphone connection), a Nokia, and a Blackberry. She used these with broadband when possible and also used a telecommunications network in Indonesia. In Australia, she was using an iPhone, a tablet, and a laptop. Like other participants, she told us: 'I check my iPhone when I'm still in bed; messages, it's the first thing I do 
and the last thing I see at night'. The platforms that Retno used depended on her mood and the specific groups that she was connecting with. She used Facebook for friends from junior school, high school, university, and activists. She said Path was the favourite app for many Indonesians, and she described it as being like a hub which can automatically be updated through Twitter or Facebook.

Wulan lived in her grandmother's old house in Indonesia. There, although she did not have a Wi-Fi connection, Wulan was also 'always online'. She described how she checked social media 'really often, every several minutes I check my phone, open my Path and check my Instagram'. She followed several Instagram fashion accounts, which was like reading the news for her, to keep up to date with 'what's happening' in the fashion world that she was part of and learn more about fashion. Like Retno, her phone was the first and last moment in her day. She described how, on waking in the morning, 'I check my phone first but it's related to the office,' to see whether there were any urgent emails or SMS messages about things that she should go into the office early for. When she went to bed, the last thing she would do involved 'checking Instagram, like seeing something that I like, browsing, yeah checking Instagram'.

Ratih was not concerned with having up-to-date technologies, but stressed the importance of having up-to-date functionality. The first thing she did in the morning was to check her WhatsApp, email, and SMS notifications on her Android, and also used Facebook and Twitter. Ratih also had a tablet but did not use it and did not even bring it to Melbourne with her as she found it too bulky. She used her laptop for work and email, and in Indonesia she had Internet access at her parents' house and her apartment.

Nadia was purposefully resistant to adopting new technologies. During the four years that she had lived in Australia she had the same old mobile phone as in Indonesia, using her laptop for Internet access. However, just before her last trip to Indonesia she had bought an iPhone and now found herself continually checking it, including checking the weather before doing her laundry. She had also recently upgraded her laptop to a Mac. When she lived in Indonesia, she accessed the Internet at work or in a café. However, when she visited just before our meeting she noted that her friends now tended to have good Internet supplier packages in their homes. She had also identified a shared workspace where with a very high-speed Internet connection that would be suitable for her and her husband to use when she moved back to Indonesia.
Digital media use and laundry are dispersed activities that are interwoven with each other and with other everyday life activities. The relationship between laundry and digital media might initially conjure up images of smart laundry technologies, apps to programme the washing machine while at work or in the car, or alerts sent to smartphones when the detergent is running out. However, we are interested in those small, frequently invisible and much more mundane ways in which people are already creating connections between laundry and digital media. These instances begin to show us how two activities which involve the use of local infrastructures, technologies and materialities, were co-evolving as participants improvised in everyday life in ways that brought them together within the same activity and process. We found laundry and digital media were entangled in three key ways, based on what participants discussed with us in recalling their lives in Indonesia, in describing their activities in Melbourne, and in indicating where digital media was used when they re-enacted their laundry processes: in Melbourne, participants used smartphone weather apps to check the weather before doing or hanging out laundry and when deciding what to wear; in both contexts, participants used social media or read while waiting for short laundry cycles (10 or $15 \mathrm{~min}$ ); they also listened to radio or music with earphones while sorting laundry, loading the washing machine, and hanging up the laundry outside. These improvisatory ways of combining digital technologies and media and laundry were practically useful and part of the sensory, embodied, and affective ways of doing laundry that participants developed in Melbourne and that were embedded in everyday life routines, activities, and priorities. We next explore how participants imagined their digital domestic futures once back in Indonesia. Before bringing these together with the adaptations and the improvisations described in this section, we will consider how digital media and laundry might become entangled in their future lives and how they may be used together to promote sustainable laundry.

\section{Envisioning Digital Futures for Sustainable Laundry}

As the new Indonesian middle classes set up and established new family homes and adopted washing machines, two aspects of environmentally sustainable laundry emerged as relevant: (1) using less water and electricity, and (2) becoming committed to using environmentally friendly products.

The futures that participants described spanned up to ten years ahead. They were purposefully mundane 
domestic futures, where digital media and professional aspirations figured and household and family futures were focused on establishing a nuclear family. These futures were also culturally specific with shared references to how life would be 'easier', with better transport systems, professional lives, and more digital and domestic technologies. Collectively, they envisioned a shared imaginary of a 'good life' in the future, which was also specific to this generation.

The future households that our women participants imagined and described to us were populated with husbands, children, and maids. They would have professional careers alongside caring for their homes and families (and laundry) and the help of a maid while they maintained control and responsibility. For example, Wulan would make her life easy. If there was a good public transport system, she would use it; otherwise, she would drive. She would have an electric stove, a single-tub washing machine, and a maid. As she explained it:

We have dirty air in Jakarta so we need to clean our house often and cleaning the house is a waste of energy; when I feel tired from cleaning, I have no energy to have a good conversation and relation with my partner and my family and my kids - not because I am too lazy to clean the house, but because I have another preference of my time.

Digital technology was significant in the imagined futures of all participants. For Wulan and Nadia, effective access to the Internet and digital technologies would be essential for running their businesses. Several participants discussed how in major cities good broadband packages were increasingly available and used alongside mobile technologies. Rizaldi had a package with a fast connection for streaming and his sons' gaming, like Nadia's friends, and Retno had arranged the technology for her parents to be able to 'skype' her in Melbourne. Their expectations of broadband and information, communication, and entertainment technologies, and mobile and locative media, were beyond those technologies afforded by our Indonesia-based participants who, although often working professionally from home, did not have home Internet packages and used smartphones at home and broadband at work. Being in Melbourne put participants in a position to be able to imagine how a future life at home might be differently lived out, and how within this the possibility of working from home with a good Wi-Fi connection and a washing machine would mean a different everyday life configuration. For example, Retno explained what her home would be like once she will have married and returned to Indonesia two years later:
I want to have a big desktop because I love to write and it is helpful for me. Usually in Indonesia, I [ . . ] just go to the coffee shop and try to write, try to find inspiration. And you know when you write sometimes you forget to have your lunch, but in the coffee shop you can: it's easy to order and there's a Wi-Fi connection; in Yogyakarta, I don't have an office, I can work everywhere. But later, if I have a family I'd like to have my own study in my house with a computer, a big computer. Actually, I want to buy that gadget here, but I am not sure about taking it back to Indonesia.

Participants also imagined that they would have their own washing machines. Most of the women participants intended to run their own businesses and/or work from home once they had children to enable them to manage their professional and domestic lives in tandem. They thought that it would be 'easy' for them to do the laundry themselves if they had a washing machine at home: a maid would not be needed for this. As shown above, environmentally sustainable activities, such as the short wash, and scheduling of laundry for drying, were entangled with participants' locative, mobile, and social media use, and with the fact that the participants would be active online, socially and commercially. It is amongst this generation of adopters of single-tub washing machines in digital environments that new forms of expertise are emerging. It is here also where real future possibilities for connecting digital technologies with sustainable washing machine use lie and where they can be imagined in relation to future infrastructures.

\section{Conclusion}

In this article, we showed how a focus on changes in mundane everyday practices can offer us new insights into the imagined futures of temporary migrants who plan to return to their home country; possibilities relating to shifts towards future environmental sustainability; and the relevance of social, digital, and material infrastructures in these shifts.

To demonstrate this, we discussed the example of how, by undertaking research with student migrants who intended to return home, we could reflect with them on what had changed in their lives and how they could subsequently imagine their possible futures. On moving countries, many facets of their lives changed - including those relating to laundry and digital media use - as they shifted from being middle-class professionals in Indonesia to studying in Australia. A design anthropological focus on how 
people improvise in relation to the contingent circumstances of their emergent everyday lives encouraged us to examine how they learnt to use washing machines; compared the use and cost of water, electricity resources, and infrastructures and the effectiveness of environmentally friendly products; reduced the number of times they would wear an item of clothing before washing it in Melbourne; felt concerned about the use of water and energy; and used digital technologies within their laundry activities. This produced insights into how, where, and why they had made changes in their everyday laundry routines and practices, how digital media and sustainability had both become integrated into these routines, and how they thought these would impact their lives back in Indonesia.

Doing research with migrants and considering their expectations and aspirations does not reveal any 'truths' about how future laundry might be more sustainable or how digital technology might be implicated in it. By extension, therefore, a focus on how mundane futures are imagined is not intended to be a predictive method. Rather, a design anthropological approach focuses our attention on imaginaries and possibilities. As we have demonstrated, by researching with people who recently acquired new frames through which to envision their futures, it is possible to access a future-oriented narrative of mundane everyday life - in the case outlined here, of laundry and previously untold stories about how digital futures might be imagined and where domestic laundry might fit into these. These imaginaries were based on everyday sensory embodied experiences and culturally embedded aspirations towards a specific kind of 'better life' along aspirational trajectories that were both personalised and culturally specific. These mundane future visions, which are culturally and practically plausible in relation to participants local knowledge, constitute a particular story about future homes and sustainable lifestyles. This differs from and thus contests and moderates those accounts offered by the narratives of 'the unrealistic utopian aspirations of smart technologies' where 'current smart homes are similarly characterized by utopian aspirations alongside a relative absence of social research conducted with people who actually live in them' (Strengers 2013).

Creating understandings of how culturally and locally relevant future imaginaries are constituted provides a basis upon which to propose possible interventions towards sustainable futures. In our example, the analysis of short-term migrants' experiences of learning how to do laundry in a new context enabled us to subsequently imagine future possibilities, which could create routes towards future sustainability when they go home. These include machine washing on short cycles (using less energy and water), using sustainable products, and entangling outdoor drying with existing uses of digital media. Our research has shown that the participants had improvised to bring together digital media and laundry in new ways as part of processes that attended to environmental sustainability. This invites us to consider how these three strands might be further bound together as infrastructural changes and emerging digital technologies create new possibilities and thus mutually support the making of emergent (but messy) sustainable laundry cultures, in which digital technologies are increasingly integrated in mundane ways alongside the growth of an emergent middle class.

To understand how sustainable futures might be lived out as part of everyday life, we need to attend to how mundane everyday practices, infrastructural possibilities, and new technologies configure in local and culturally specific ways. To achieve this, we argue, we need new experimental methods which invoke possible futures through interventions in the present. Researching with temporary migrants offers a novel approach, since, rather than requiring the researcher to create experimental conditions, it draws on changes and new configurations that the migrant participants themselves explore and reflect on.

\section{Acknowledgements}

The research discussed in this article was funded through a partnership with Unilever. We thank our research colleagues at Unilever for their collaboration, and we thank the participants in our research for their time and their interest and willingness to be part of this project.

SARAH PInK is Director of the Emerging Technologies Research Lab at Monash University, where she has a joint appointment as Professor of Design and Emerging Technologies in the Faculties of Information Technology and Art, Design and Architecture. Her interdisciplinary research brings design anthropology into collaboration with other disciplines and partners inside and outside academia. Sarah's recent books include Imagining Personal Data (2019), Atmospheres and the Experiential World (2018), Uncertainty and Possibility (2018), Making Homes (2017), Anthro- 
pologies and Futures (2017), Theoretical Scholarship and Applied Practice (2017), Digital Ethnography: Principles and Practice (2016), Doing Sensory Ethnography (2015), and Doing Visual Ethnography (2013). Public dissemination projects include www.laundrylives.com (2015) and www.energyanddigitalliving.com (2014). E-mail: sarah.pink@monash.edu

John Postill is a Senior Lecturer in Communication at RMIT University in Melbourne. His publications include The Rise of Nerd Politics (2018), Digital Ethnography (2016), Localising the Internet (2011), and Theorising Media and Practice (2010). He is currently writing an anthropological history of media and communication titled Runaway Media and his first novel, Life of Pinas. E-mail: john.postill@rmit.edu.au

\section{Note}

1. The authors were not involved with teaching any of the participants.

\section{References}

Akama, Y., S. Pink, and S. Sumartojo (2018), Uncertainty and Possibility (London: Bloomsbury).

Anand, N., A. Gupta, and H. Appel (2018), The Promise of Infrastructure. Durham, NC: Duke University Press.

Ansori, M. (2009), 'Consumerism and the Emergence of a New Middle Class in Globalizing Indonesia', Explorations 9: 87-97, https://core.ac.uk/download/ pdf/5099980.pdf.

Carrieri, M., M. Crete-Nishihata, D. Dalek, R. Deibert, ... and G. Wiseman (2013), 'An Overview of Indonesian Internet Infrastructure and Governance', Citizenlab.ca, 25 October, https://citizenlab.ca/2013/10/ igf-2013-an-overview-of-indonesian-internet-infra structure-and-governance/.

Das, K., M. Gryseels, P. Sudhir \& K. T. Tan (2016) ‘Unlocking Indonesia's Digital Opportunity', McKinsey Indonesia Office October 2016. Available online at https://www.mckinsey.com/featured-insights/asiapacific/unlocking-indonesias-digital-opportunity, accessed $10^{\text {th }}$ August 2019.

Department of Foreign Affairs and Trade (DFAT) (N. D.), 'Indonesia Country Brief', http://www.dfat.gov .au/geo/indonesia/pages/indonesia-country-brief .aspx.
Fincher, R. and K. Shaw (2011), 'Enacting Separate Social Worlds: "International" and "Local" Students in Public Space in Central Melbourne', Geoforum 42: 539-549, https://doi.org/10.1016/j .geoforum.2011.05.002.

Gomes, C., M. Berry, B. Alzougool, and S. Chang (2014), 'Home Away from Home: International Students and Their Identity-Based Social Networks in Australia', Journal of International Students 4, no. 1: 2-15, https://www.ojed.org/index.php/jis/article/ view/493.

Halse, J. (2013), 'Ethnographies of the Possible', in Design Anthropology: Theory and Practice, (ed.) W. Gunn, T. Otto, and R. Charlotte-Smith (London: Bloomsbury), 180-196.

Highmore, B. (2011), Ordinary Lives: Studies in the Everyday (London: Routledge).

Hjorth, L., S. Pink, H. Horst, J. Sinanan, K. Ohashi, F. Kato, and B. Zhou (2018), 'Beyond Emoji Play: Paralinguistics and Intergenerational Care-at-Distance', in Transnational Migrations in the Asia-Pacific: Transformative Experiences in the Age of Digital Media, (ed.) C. Gomes and B. S. A. Yeoh (Lanham, MD: Rowman and Littlefield), 129-152.

Ingold, T. (2013), Making: Anthropology, Archaeology, Art and Architecture (London: Routledge).

Jones, C. (2010), 'Materializing Piety: Gendered Anxieties about Faithful Consumption in Contemporary Indonesia', American Ethnologist 37, no. 4: 617-637, https://doi.org/10.1111/j.1548-1425.2010.01275.x.

Kismono, G. (2011), 'The Relationships between Job Embeddedness, Work-Family Conflict, and the Impact of Gender on Turnover Intention: Evidence from the Indonesian Banking Industry' (PhD Diss., Curtin University, Australia), https://espace.curtin .edu.au/handle/20.500.11937/2256.

Komito, L. and J. Bates (2009), 'Virtually Local: Social Media and Community among Polish Nationals in Dublin', in Aslib Proceedings 61, no. 3: 232-244, https://doi.org/10.1108/00012530910959790.

Kooy, M. and K. Bakker (2008), 'Technologies of Government: Constituting Subjectivities, Spaces and Infrastructures in Colonial and Contemporary Jakarta', International Journal of Urban and Regional Research 32, no. 2: 375-391, https://doi.org/10.1111/ j.1468-2427.2008.00791.x.

Madianou, M. and D. Miller (2011), Migration and New Media: Transnational Families and Polymedia (New York: Routledge).

Maller, C. and Y. Strengers (2013), 'The Global Migration of Everyday Life: Investigating the Practice Memories of Australian Migrants', Geoforum 44: 243252, https://doi.org/10.1016/j.geoforum.2012.09.002. 
Melissa, E., M., A. Hamidati, M. S. Saraswati, and A. G. Flor (2013), 'Investigating the Potentials of Social Media to Support Women Entrepreneurship in Indonesian Urban Areas', in Proceedings of the Sixth International Conference on Information and Communications Technologies and Development (New York: ACM Press), 92-95.

Miller, D. (2011), Tales from Facebook (Cambridge: Polity Press).

Nilan, P., L. Parker, L. Bennett, and K. Robinson (2011), 'Indonesian Youth Looking towards the Future', Journal of Youth Studies 14, no. 6: 709-728, https:// doi.org/10.1080/13676261.2011.580523.

Nilan, P. and P. Utari (2008), 'Meanings of Work for Female Media and Communication Workers', in Women and Work in Indonesia, (ed.) M. Ford and L. Parker (London: Routledge), 136-154.

Pink, S. (2017), 'Ethics in a Changing World: Embracing Uncertainty, Understanding Futures, and Making Responsible Interventions', in Working in the Between: Theoretical Scholarship and Applied Practice, (ed.) S. Pink, V. Fors, and T. O'Dell (Oxford: Berghahn), 29-51.

Pink, S. and N. Astari (dirs) (2015), Laundry Lives (Melbourne: RMIT University).

Pink, S., V. Fors, and M. Glöss (2018), 'The Contingent Futures of the Mobile Present: Beyond Automation as Innovation,' Mobilities 13, no. 5: 615-631, https:// doi.org/10.1080/17450101.2018.1436672.

Pink, S. and K. Leder Mackley (2014), 'Reenactment Methodologies for Everyday Life Research: Art Therapy Insights for Video Ethnography', Visual Studies 29, no. 2: 146-154, https://doi.org/10.1080/ 1472586X.2014.887266.

Pink, S., K. Leder Mackley, and R. Morosanu (2015), 'Hanging Out at Home: Laundry as a Thread and Texture of Everyday Life', International Journal of Cultural Studies 18, no. 2: 209-224, https:// doi.org/10.1177/1367877913508461.

Pink, S., K. Leder Mackley, R. Morosanu, V. Mitchell, and T. Bhamra (2017), Making Homes: Ethnography and Design (London: Bloomsbury).
Pink, S. and J. F. Salazar (2017), 'Anthropologies and Futures: Setting the Agenda', in Future Anthropologies, (ed.) J. F. Salazar, S. Pink, A. Irving, and J. Sjöberg (Oxford: Bloomsbury), 3-22.

Shove, E. (2003), Comfort, Cleanliness and Convenience: The Social Organization of Normality (Oxford: Berg).

Simone, A. and A. U. Fauzan (2013), 'Majority Time: Operations in the Midst of Jakarta', The Sociological Review 61, no. S1: 109-123, https:// doi.org/10.1111/1467-954X.12056.

Smith, R. C. and T. Otto (2016), 'Cultures of the Future: Emergence and Intervention in Design Anthropology', in Design Anthropological Futures, (ed.) R. C. Smith, K. T. Vangkilde, M. G. Kjærsgaard, T. Otto, J. Halse, and T. Binder (London: Bloomsbury Academic), 19-36.

Strengers, Y. (2013), Smart Energy Technologies in Everyday Life: Smart Utopia? (London: Palgrave Macmillan).

Titley, G. (2008), 'Media Transnationalism in Ireland: An Examination of Polish Media Practices', Translocations: The Irish Migration, Race and Social Transformation in Review 3, no. 1: 29-49, http://mural .maynoothuniversity.ie/2359/.

Tsuda, T. (2019), 'Conclusion: Interrogating Return Ambivalent Homecomings and Ethnic Hierarchies', in Diasporic Returns to the Ethnic Homeland: The Korean Diaspora in Comparative Perspective, (ed.) T. Tsuda and C. Song (Basingstoke, UK: Palgrave Macmillan), 238-259.

Watson, S. (2015), 'Mundane Objects in the City: Laundry Practices and the Making and Remaking of Public/Private Sociality and Space in London and New York', Urban Studies 52, no. 5: 876-890, https:// doi.org/10.1177/0042098014531630.

Wijaya, M. and T. Tezuka (2013), 'Measures for Improving the Adoption of Higher Efficiency Appliances in Indonesian Households: An Analysis of Lifetime Use and Decision-Making in the Purchase of Electrical Appliances', Applied Energy 112, no. C: 981-987, https://doi.org./10.1016/j.apenergy.2013.02.036. 